\title{
Leadership: Philosophical Perspectives and Qualitative Analysis of Ethics-Looking Back, Looking Forward, Looking Around
}

\author{
Karianne Kalshoven ${ }^{1}$ D $\cdot$ Scott Taylor ${ }^{2}$
}

Received: 11 December 2017 / Accepted: 21 January 2018 / Published online: 29 January 2018

๑) Springer Science+Business Media B.V., part of Springer Nature 2018

This virtual special issue of the Journal of Business Ethics explores the topic, and the related section at the journal, of Leadership: Philosophical Perspectives and Qualitative Analysis of Ethics. It introduces a collection of seven papers previously published at the journal and gives thought to future development of scholarship at the intersection of leadership and ethics. As two people active in the business ethics scholarly community, we would like to share our views on the field of philosophical and qualitative approaches to the intersection of ethics and leadership. Why do you and we study this very relevant topic? If we only take a few short minutes to think about this question, we find ourselves with a wide range of responses. For us specifically, we do this work to try to change the world for the better, idealistic as that sounds. That means that we see our jobs as more than just conducting research, providing education, writing scientific articles, or being section editor of this journal. We see that we are all role models, in terms of academic practice and leadership practice. In this respect, we are under a greater obligation than some to practice what we preach. We are also committed to thinking through implementation of the theories and suggestions we develop in our analyses, to inform the use and effect of ethics for a better world. This journal is a key source of data, theory, and practice, and always has been. At this key moment, we provide here a brief history of leadership/ethics debates in this journal and relate them to contributions published in other spaces.

Karianne Kalshoven

Karianne@acil.nl

Scott Taylor

s.taylor@bham.ac.uk

1 Amsterdam Center for Integrity and Leadership, Amsterdam, The Netherlands

2 Birmingham Business School, University of Birmingham, Birmingham, UK

\section{Looking Back}

It is notable that the first editorial statement for this journal focuses on thought about 'all human action aimed at securing a good life' (Michalos 1982: 1). A list of the various subject areas usually found in business schools is provided in that editorial, that does not include leadership. To date, a very basic search using the term 'leadership' on work published in this journal between 1982 and 2012 returns 2700 results. A more focused search, again using the term 'leadership' but limited only to its appearance in article titles in this same 30 year period, returns a mere 153 results. The first such paper appears 5 years into the journal's life, and subsequent years show one to five papers published each year, with a number of years showing none. Then in 2007, we see seven; in 2008, ten; in 2009, eleven; and then a steady rise with each passing year, to 2016, where we count thirty-two.

Even though this section focuses on qualitative or conceptual research on leadership and business ethics, we recognize that there can be something comforting in numbers as a basis for understanding. So what comfort is there here? Firstly, it seems to us to show more attention being paid to the ideas and practices that we call leadership or leading. That in turn means, secondly, that the significance of people occupying positions of power, or the exercise of power through leading, are being brought into our understanding of business ethics. Thirdly, it clearly indicates how leadership, leaders, and leading have become more central to our understanding of management and organization more generally.

For us, this is all good news, even if we don't find every published contribution meaningful. We believe that analyzing the triad of leadership as language, leaders as people, and leading as practice are all key to developing what Michalos called 'a good life' as framed by management, organization, and business in its broadest sense. Despite changes to the journal and the people who maintain it over time, we believe that remains a key statement of what contributions to this section can aim toward. 
When we read the articles that make up the numbers, some patterns are clear. The philosophical aspect of how leadership and ethics intersect is often satisfied with reference to historical and contemporary 'Greats,' such as Plato (Korabik 1990), MacIntyre (Sinnicks 2016), or Levinas and Gilligan (Grandy and Sliwa 2017). This can extend across cultures, with contributions explaining the ethical particularities of, for example, leadership in non-US (the default culture) countries such as Japan (Taka and Foglia 1994; Witt and Stahl 2016). A related series of contributions bring what are sometimes called 'traditional' (Pava 2001) or faith-based (Wang and Hackett 2016) ethics to understanding leadership. There is not always a clear differentiation between the secular metaphysical and the religiously spiritual, perhaps reflecting what Weber observed in the sociocultural dedifferentiation of religious belief systems during modernity, placing them alongside secular systems of thought such as humanism and Marxism (Bell and Taylor 2016). Alongside that, this journal has encouraged reflections on our educational practice, in work with under- and postgraduate students to explore leadership (Harshman and Harshman 2007), or the absence/presence of ethical education in business schools (especially when capitalism is experiencing one of its many moments of crisis; see Bassiry 1990, or Painter-Morland et al. 2016). There is also a strong thread of gender, or sex, as a means of understanding (un)ethical leadership practices and their effects, or the ethics of elevation to and occupation of positions of leadership (Korabik 1990; Klettner et al. 2016).

\section{Looking Forward}

As some of this work demonstrates, there has been a broad interpretation of the notion of business ethics. Following the call to both broaden the intellectual base and, more importantly, focus on ethics (Greenwood and Freeman 2017) across the journal, this is an ideal moment to encourage the same in this section. In relation to leadership, leading, and leaders, this reorientation carries a specific burden. It is possible to fallaciously assume that the ethical implications of an analysis are transparent, if it deals with an aspect of business, organization, and management that is obviously controversial, such as leadership. Many of the most common leadership analytics also fall into this category: gender, globalization, power, race, and ethnicity are all obviously ethical concerns but are rarely disentangled. And yet, as the contributions that are most germane to the journal remit show analysis of these dynamics to produce a contribution to business ethics is not obvious. There are, we think, some obvious ways into these issues in relation to ethical thinking that are not as yet as well represented in this section as they might be-feminism, post-colonial theory, post-structural thought, and intersectionality are all available to us as researchers and reflexive educators, for example, but less prominent in this section than elsewhere.

\section{Looking Around}

Good examples of this kind of work are regularly published in both generalist and specialist journals (Price 2017; Simola et al. 2010), and in book form (Sinclair 2016; Wilson 2016). There is no good reason for this absence or neglect of this kind of thinking in this section-it provides the foundation for much of what is presented in at the largest general conferences, such as the US Academy of Management, the European Academy of Management, or the Indian Academy of Management. And these perspectives are even more obviously present in the work presented to more specialist meetings, such as the biennial Gender, Work and Organization and Critical Management Studies conferences. This section is deliberately designed to be open to all, as a part of a journal that is committed to publishing work that breaks down or ignores the socially constructed barriers and boundaries of knowledge production that those who seek paradigm consensus for 'organizational science' desire.

We would say this openness also underpins the journal's approach to the 'lead' term. From the beginning (Enderle 1987), individual, corporate, and 'wider' (i.e., social, cultural, political) are all seen as equally significant. This continues to the present day, for example, Davis' (2016) account of the intersection of leader, leadership, society, and business through the example of the British Co-Operative Movement is exemplary in this respect. Leadership studies is a field plagued by worries about definitional variety. We would encourage those submitting work to this journal to be comfortable with the idea that a research field can tolerate a wide range of plants growing in it and that there are no weeds (van Maanen 1995). As long as the definition makes sense in its own terms, and works with the methodology or epistemology, then the plant belongs in this garden. Finally, in relation to leadership, contributors to this area in this journal have also been clear that '... leadership is not the answer to all problems nor the key to prosperity, happiness and salvation' (Enderle 1987: 663), a message that many researchers working in leadership studies might heed more today.

Finally, this short editorial represents the moment when the occupant of the section editor chair changes. For 2 years, Karianne Kalshoven (Amsterdam Center for Integrity and Leadership, The Netherlands) has taken care of and developed this section. Karianne is now handing over to Scott Taylor (Birmingham Business School, University of Birmingham, UK) to continue her good work. Scott has been researching and teaching on leadership and ethics for more than a decade and has published on these subjects in a range 
of journals (Leadership, Organization, Journal of Management Education), and in edited scholarly collections and textbooks.

\section{Compliance with Ethical Standards}

Human and Animal Rights This article does not contain any studies with human participants or animals performed by any of the authors.

Informed Consent The Editors-in-Chief, Ed Freeman and Michelle Greenwood, asked the authors to write this editorial. For this type of study formal consent is not required, because it is a retrospective editorial. Informed consent was obtained from all individual participants included in the study.

\section{References}

Bassiry, G. (1990). Ethics, education, and corporate leadership. Journal of Business Ethics, 9(10), 799-805.

Bell, E., \& Taylor, S. (2016). Spirituality. In M. Greenwood, R. Mir, \& H. Willmott (Eds.), Routledge companion to philosophy in organization studies. London: Routledge.

Davis, P. (2016). Retrieving the co-operative value-based leadership model of Terry Thomas. Journal of Business Ethics, 135(3), $557-568$

Enderle, G. (1987). Some perspectives of managerial ethical leadership. Journal of Business Ethics, 6(8), 657-663.

Grandy, G., \& Sliwa, M. (2017). Contemplative leadership: The possibilities for the ethics of leadership theory and practice. Journal of Business Ethics, 143, 423-440.

Greenwood, M., \& Freeman, R. E. (2017). Focusing on ethics and broadening our intellectual base. Journal of Business Ethics, 140, $1-3$.

Harshman, C., \& Harshman, E. (2007). The Gordian knot of ethics: Understanding leadership effectiveness and ethical behaviour. Journal of Business Ethics, 78, 175-192.
Klettner, A., Clarke, T., \& Boersma, M. (2016). Strategic and regulatory approaches to increasing women in leadership: Multilevel targets and mandatory quotas as levers for cultural change. Journal of Business Ethics, 133(3), 395-419.

Korabik, K. (1990). Androgyny and leadership style. Journal of Business Ethics, 9(4/5), 283-292.

Michalos, A. C. (1982). Editorial: Purpose and policy. Journal of Business Ethics, 1(1), 1.

Painter-Morland, M., Sabet, E., Molthan-Hill, P., Goworek, H., \& de Leeuw, S. (2016). Beyond the curriculum: Integrating sustainability into business schools. Journal of Business Ethics, 139(4), $737-754$.

Pava, M. (2001). The many paths to covenantal leadership: Traditional resources for contemporary business. Journal of Business Ethics, $29(1 / 2), 85-93$.

Price, T. (2017). A "critical leadership ethics" approach to the Ethical Leadership construct. Leadership. https://doi.org/10.1177/17427 15017710646

Simola, S., Barling, J., \& Turner, N. (2010). Transformational leadership and leader moral orientation: Contrasting an ethic of justice and an ethic of care. The Leadership Quarterly, 21, 179-188.

Sinclair, A. (2016). Leading mindfully. Melbourne: Allen \& Unwin.

Sinnicks, M. (2016). Leadership after virtue: MacIntyre's critique of management reconsidered. Journal of Business Ethics,. https:// doi.org/10.1007/s10551-016-3381-6.

Taka, I., \& Foglia, W. (1994). Ethical aspects of "Japanese leadership style". Journal of Business Ethics, 13(2), 135-148.

Van Maanen, J. (1995). Style as theory. Organization Science, 6(1), 133-143.

Wang, G., \& Hackett, R. (2016). Conceptualization and measurement of virtuous leadership: Doing well by doing good. Journal of Business Ethics, 137(2), 321-345.

Wilson, S. (2016). Thinking differently about leadership: A critical history of leadership studies. Cheltenham: Edward Elgar.

Witt, M., \& Stahl, G. (2016). Foundations of responsible leadership: Asian versus Western executive responsibility orientations towards key stakeholders. Journal of Business Ethics, 136(3), 623-638. 